Title:

\title{
The influence of patient gender on medical and psychology students' illness attributions: Experiences with a narrative technique
}

\section{Author names:}

Ilona Csörsz

University of Debrecen, Medical and Health Sciences Center, Faculty of Public Health, Department of Behavioural Sciences

98. Nagyerdei krt. P.O.Box:45., H-4032 Debrecen, Hungary

csorsz.ilona@sph.unideb.hu

Péter Kakuk

University of Debrecen, Medical and Health Sciences Center, Faculty of Public Health, Department of Behavioural Sciences

98. Nagyerdei krt. P.O.Box:45., H-4032 Debrecen, Hungary

kakuk.peter@sph.unideb.hu

Eszter Molnár Mills

Formium Development, UK

161 Lancaster Road, Enfield, London, EN2 0JN, United Kingdom

eszter.molnar-mills@formium.co.uk

Péter Molnár

University of Debrecen, Medical and Health Sciences Center, Faculty of Public Health, Department of Behavioural Sciences

98. Nagyerdei krt. P.O.Box:45., H-4032 Debrecen, Hungary

pmolnardeoec@gmail.com

János Máth

University of Debrecen, Faculty of Humanities, Department of Psychology 
Egyetem tér 1. H-4010 Debrecen, Hungary

math.janos@arts.unideb.hu

Márta Csabai

University of Szeged, Faculty of Humanities, Department of Psychology

Dugonics tér 13. H-6720 Szeged, Hungary

csabaim@mtapi.hu

\title{
Corresponding author:
}

Ilona Csörsz

University of Debrecen, Medical and Health Sciences Center, Faculty of Public Health, Department of Behavioural Sciences

98. Nagyerdei krt. P.O.Box:45., H-4032 Debrecen, Hungary

Tel.: 3652 255406; Fax: 3652 255487;

email: csorsz.ilona@sph.unideb.hu

\section{Keywords:}

gender stereotype, symptom interpretation, illness narrative, future professionals, somatisation

\begin{abstract}
:
We attempted to identify whether and how the gender of the patient influences interpretations of an illness narrative. We investigated how medical and psychology undergraduates' $(n=313)$ views change according to the patient's gender, students' gender, and field of study. A short story about a female patient was chosen as stimulus material, and a gender modified version with a male protagonist was created for comparison. Responses were content analyzed by qualitative and quantitative methods. The female patient elicited more detailed descriptions, and somatizing attributions. The gender of students had a stronger impact on responses than their field of study.
\end{abstract}




\section{Introduction}

In recent decades a number of medical psychological and anthropological studies have shown that opinions in connection with illnesses and illness experiences depend on the wider social milieu and on the specialized culture of health care (Aronowitz, 1998). Due to the widespread use of mass media and the internet, a body of research has indicated that the illness representations of laypersons are not radically different from those of health care specialists (Arksey, 2008). One of the foremost agreements is that in Western cultures patients dichotomize symptoms according to their "somatic” or ,psychological” background in the same way as health care specialists. Furthermore, the current tendencies for medicalization are present among both patients and specialists; and psychologization is also similarly widespread (Prior, 2003).

Many earlier studies, including our previous research, have suggested that both specialists and patients regard illnesses with a psychological background of lesser importance for receiving treatment (Bishop et al., 1987; Peters et al., 1998; Csabai and Szili, , 2010). Results of these studies indicate that laypersons' judgments regarding their symptoms are often directly related to the patient's other - life situation, psychological, etc. - problems. It is very important to emphasize that the presence of this relationship applies in the case of most specialists, while attribution processes and gender stereotypes influence their interpretation of symptoms (Ruiz and Verbrugge, 1997).

A general model of symptom attribution was developed by Robbins and Kirmayer (1991), who categorized attribution styles as normalizing, somatizing and psychologizing. Earlier studies confirmed that somatizing attribution and the related illness behaviour (perception of symptoms, request for medical consultation) shows gender differences (Creed and Barsky, 2004). "Somatizing" patients - lacking medical explanation for their symptoms - are predominantly women. The fact that women usually report bodily symptoms more frequently than men within the same period, can be explained to a significant extent by the notion that the act of complaining, the confession of physical weakness, is itself perceived to be a feminine attribute (Gijbers van Wijk et al., 1999; Fletcher et al., 2002). This stereotype determines judgments concerning illness behaviour. According to Foss and Sundby's review (2003) hospital staff generally perceive the illness behaviour of men as relatively unproblematic compared to women, with men being seen as taking up little time, having less information need, handing over responsibility, and more easily accepting professional decisions. The expression of symptoms by female patients is more confused, obscured, and 
according to professionals they are more time-consuming and have more extensive information needs.

Numerous studies have concluded that health care professionals' manner of treatment is influenced by gender differences. These studies highlight that female doctors spend more time with their patients, their interactions are characterized more by emotional communication, and they are more likely to discuss psycho-social topics with their patients (Hall and Roter, 1998). Female doctors give more support to developing the healing relationship, they frequently facilitate partnership with patients, they are less dominant in the doctor-patient consultation processes, and they are less protective regarding their professional prestige (Kerssens et al., 1997; Roter et al., 2002). They are more inclined to react to patients' concerns, giving more emotional feedback, compared to male doctors (Meeuwesen et al., 2002; Roter, 2001; Sleath and Rubin, 2002). Regarding therapeutic effectiveness, only the female doctor - female patient pairing has proved to be significantly better, in those cases where a significantly higher degree of mutual support and partnership has been reached (Derose et al., 2001; Van den Brink-Muinen et al., 2002).

Research studies have also shown out the presence of gender bias in the professional diagnostic process of psychosomatic diseases. The authors of a paper-case study with resident doctors about irritable bowel syndrome called attention to the danger of knowledge-mediated gender bias (Hamberg et al., 2004). It means that if such a biased knowledge is consolidated, the doctor would apply it partly unintentionally, but mainly automatically - in the later evaluation of patients. It has been also revealed that biasing elements can be found in undergraduate medical education as well, for example in the hidden gender stereotypes of medical textbooks (Dijkstra et al., 2008). Researches however have not yet explored the formation of this biased knowledge in association with symptom attribution, and its relationship with the general image which the student (or professional) forms about the patient. We suppose that the way in which these attributions are connected - or not connected - to the patient's life history, may substantially determine the deeper understanding and final professional evaluation of the patient's presented problem. Further we wanted to examine the role of somatizing (medicalizing) and psychologizing tendencies in the construction of gender-related attributions. That's why we compared representations of medical and psychology students, supposing that their different study backgrounds and ways of professional socialisation might have an impact on the process of professional knowledge formation. 


\section{Methods}

The developments of symptom-representations, attributions and cognitive schemas have been investigated using a specific narrative projective technique that was developed by us (Csörsz et al., 2011). A special feature of this projective method is that instead of presenting a clinical vignette for reflection, or an interview analysis, we use a literary short story that presents an illness narrative as a stimulus material, a "projective surface". We have developed this method because the application of clinical vignettes calls forth traditional interpretative tasks that mobilize cognitive skills without being able to provide information regarding significant emotional content and socio-cultural representations, which are usually disguised in the background.

We proceeded from the idea that the reception and understanding of works of art - for example short stories - needs concentrated attention called empathic understanding (Patterson, 1985; Mar et al., 2009). A short story presents a patient in a specific perspective enabling the illness and symptoms to appear embedded in the life history of the patient. The short story as a projective surface allows us to follow the diagnostic and interpretative process in a condensed manner. According to current insights in cognitive science, affective components significantly influence the formation of cognitions (Jenkins and Oatley, 2006). As an important feature of this specific indirect method, illness and symptoms are presented within their specific setting, within a network of emotions and social relationships. The reader is more likely to identify him/herself with those characters in the story who have an already contoured profile in the reader's experience. Undergraduate psychology and medical students - as "undeveloped" professionals - are likely to identify themselves equally easily with both the professional and lay characters of the story.

The short story that was used has been selected by us using the following criteria:

- $\quad$ the story should not contain an exact diagnosis

- $\quad$ various, but not elaborated characters should appear

- $\quad$ the narrative style should be highly neutral, emotionally less colored

These criteria are necessary in order to create adequate conditions for revealing associations. A sketchily written story creates an uncertain situation that - as people automatically attempt to complete the whole - acts as a projective surface. Projections are also facilitated by displacement, as the story is set in the 1930's.

The short story that best fitted our above-mentioned criteria was Lajos Nagy's The Patient (1937), which is just three pages long, and can be simply summarized as follows. 1. An 
elderly couple arrives at a hospital reception to visit their adult granddaughter (Ilonka, the protagonist of the story). 2. A worried husband asks questions from the head of the hospital department about his wife's (Ilonka's) operation. 3. A female patient (Ilonka) after an operation complains to her roommate that her relatives fail to care about her.

The short story focuses on a female patient, Mrs. Ilonka Szankó, who has been operated on because of a tumour (not further specified). She feels bad because as she awakens after the operation she realizes that she is alone. This is all the story tells us about the disease. As for her husband, we know that he is worrying about the result of the histological examination. In an important scene a dialogue takes place between the husband and the doctor who performed the operation. Grandparents, full of anguish, are further characters in the story.

We also developed a gender-modified version of the story, where the protagonist was represented as a man, and the doctor had a dialogue with the wife. Some minimal alterations were needed, as we exchanged the name Mrs Ilonka Szankó for the name Mr Balint Szankó, and we wrote "husband" instead of "wife". With this modification we attempted to investigate particularly the interdependent factors of the gender aspects of the patient role. One group of respondents received the original version of the short story, and the other group received the modified gender version. The research subjects were volunteers, who received the story in a university environment, but outside teaching hours.

We constructed a self-report questionnaire for gathering analysable data on respondents' associations from the story, their attributions related to the patient and her/his illness, and about their attitudes and stereotypes. The questionnaire contained 23 open-ended items that support and reveal the process of projection as the story's characters and threads became concrete images in the respondent's imagination. Questions focused on representations related to the patient, to the illness, to the patient role, and to the healing role. We have attempted to expand in time their imaginings regarding the story with questions on events that were situated beyond the written story; those which occurred before hospitalization, and also future events both within and outside the hospital. A special group of questions were related to the emotions of the respondents regarding the protagonist, the doctor, and the story as a whole. We analyzed responses according to respondents' sex, age and field of study.

Questionnaires were filled out by 313 students, of whom 183 received the original and 130 the gender modified version of the story. Respondents were medical students from their $1^{\text {st }}$ and $3^{\text {rd }}$ year $(n=189)$, and psychology students from their $1^{\text {st }}$ and $3^{\text {rd }}$ year $(n=124)$ at the University of Debrecen, Hungary. They were informed that participation in the study was 
voluntary. The short story was read to the students by a researcher and consequently they completed the questionnaire form.

\section{Data recording and analysis}

As a first step, we read through the completed questionnaires for screening and selecting relevant information. This was followed by the identification of themes that appeared in the text. Content analyses of questionnaires were undertaken by two independent raters, who compared their results, and developed content categories. They identified 31 different categories in total, 13 of which were related to the patient (e.g. age, employment, body weight, appearance, extroversion-introversion, desires, fears, marriage, important people, continuation of the story). In relation to the illness we identified 10 categories (e.g. location of the problem, etiology as psychological/physical/lifestyle, previous events, hospital events). In relation to the doctor, there were 5 categories (e.g. age, internal/external features, would the respondent wish to be treated by him/her) and there were 3 further categories describing the personal emotions of respondents. Coding was carried out by two independent raters, and later was verified by the authors. Inter-rater reliability (as measured by Kappa) between the raters was within the range of 0,52-0,87. Responses with unclear categories were discussed by the raters in order to reach a consensus. We assigned binary codes corresponding to content categories to the data, using the developed categories. Data was analyzed using SPSS and LEM programmes. The statistical methods applied were ANOVA, khi square tests and loglinear analysis.

\section{Results and Discussion}

\section{Lack of response and its relationship with the patient's gender}

The mental representation of the female and male patient-role showed a significant difference that manifested early in the response rate of the two groups. There were more incomplete and shorter responses in the group where the patient - the protagonist of the story - was presented as a man. The average number of words per questionnaire was 53,2 in the case of the male patient, compared to 108,4 for the female patient. Moreover, male respondents gave significantly fewer responses to questionnaire items and skipped more items than females. As these results emerged, we presumed that it could be explained by the previously cited and well-known phenomenon that men tend to talk about disease less frequently than women 
(Addis and Mahalik, 2003). In order to verify this with statistical methods, we created the "missing answer" category to investigate whether the value of this variable depended on the respondent's sex, field of study or the gender of the patient in the short story. The method applied was multivariate ANOVA. We obtained the following results:

The interaction of respondent's sex and field of study appeared to be significant $[\mathrm{p}=0,005 ; \mathrm{F}(1,305)=7,82]$, as was separately the gender of patient $[\mathrm{p}<0,001$; $\mathrm{F}(1,305)=18,85]$. The missing answer appeared more frequently among male medical students regarding all of the variables, compared to the other three groups. As this data showed, incomplete questionnaire submission was the most frequent among male medical students.

The effect of the patient's gender appeared to be similar: the missing answer category appears significantly $(\mathrm{p}<0,001)$ more frequently if the patient is a man (male/female patient: 10,37 / 9,03 missing answers). This means that in describing the story's protagonist as a man, skipping a question or giving briefer answers were more typical.

We further calculated the frequency of the missing answer category separately for those variables that formed questions on the background of the illness, and on its etiology. These were events before hospitalization, etiological factors and "significant others" who have some role in the patient's life. Herein we also analyzed whether, and how, the number of missing answers depends on the sex of the respondents, on their field of study, and on the patient's gender. According to our results, the interaction between the three independent variables proved to be significant $(\mathrm{p}=0,049 ; \mathrm{F}(1,305)=3,89]$. For an adequate interpretation of this interaction we analyzed separately the effect of sex and field of study, first in the case of the male patient, and then in the case of the female patient. In the case of the male patient the interaction between sex and field of study is significant $[\mathrm{p}=0,001 ; \mathrm{F}(1,126)=11,243]$.

In the case of the female patient, only the field of study had a significant effect $[p=0,024$; $\mathrm{F}(1,179)=5,15]$. In the case of the male patient we developed the following interpretation of these interactions: male medical students rarely gave information regarding the etiology of the illness, and its embeddedness in the life history of the patient. Female psychology students gave less such information compared to males. If the presented patient was a woman, then medical students - independent of their sex - typically gave fewer responses to such questions compared to psychology students. (See Table 1.)

Finally, we analyzed the frequency of the missing answer category among categories describing the patient as a person (categories such as his/her profession, body weight, appearance, egoism, self-confidence, optimism). In this case, the respondent's sex $[p=0,003$; $\mathrm{F}(1,305)=9,05]$ field of study $[\mathrm{p}=0,004 ; \mathrm{F}(1,305)=8,49]$ and the gender of the patient 
$[\mathrm{p}<0,001 ; \mathrm{F}(1,305)=20,89]$ had separate impacts. According to this, there are more skipped answers if the respondent was male, if the respondent was a medical student, and if the presented patient was a man. (See Table 2.)

\begin{tabular}{|l|c|c|c|c|}
\hline \multirow{2}{*}{ Patient's gender } & \multicolumn{2}{|c|}{ Medical student } & \multicolumn{2}{c|}{ Psychology student } \\
\cline { 2 - 5 } & Male & Female & Male & Female \\
\hline Male & 6,00 & 5,24 & 4,77 & 5,70 \\
Female & 5,32 & 5,03 & 4,60 & 4,69 \\
\hline
\end{tabular}

Table 1: Number of missing answers on the etiology of the problem

\begin{tabular}{|c|c|c|c|c|c|}
\hline \multicolumn{2}{|c|}{ Student's gender } & \multicolumn{2}{c|}{ Field of study } & \multicolumn{2}{c|}{ Patient's gender } \\
\hline Male & Female & $\begin{array}{l}\text { Medical } \\
\text { student }\end{array}$ & $\begin{array}{l}\text { Psychology } \\
\text { student }\end{array}$ & Male & Female \\
\hline 3,58 & 3,12 & 3,57 & 3,13 & 3,7 & 3,04 \\
\hline
\end{tabular}

Table 2: Number of missing answers describing the patient

Summarizing the above mentioned results, it can be ascertained that the male patient appears in the imagination of the respondents as a much more simple and unsophisticated character attracting moderate projections. Furthermore, both in the case of the male and female patient we found a significant correspondence between the patient's gender and representations regarding age (under/over 35, $\chi^{2}=11,9 ; \quad \mathrm{df}=1 ; \mathrm{p}=0,001$ ), profession (no answer/administrator/inactive/intellectual/service/manual worker, Khi=78,5, $\mathrm{df}=5, \mathrm{p}<0,001$ ), body weight (no allusion/thin/average/overweight, $\chi^{2}=5,9 ; \mathrm{df}=2 ; \mathrm{p}=0,005$ ), self-confidence (no answer/irresolute $\chi^{2}=3,94 ; \mathrm{df}=1 ; \mathrm{p}=0,047$ ), etiological-psychological factors (no answer/personal stress/family stress, $\left.\chi^{2}=8,7 ; \mathrm{df}=2 ; \mathrm{p}=0,013\right)$ and representations in connection with events before getting into the hospital (no answer/family problem, $\chi^{2}=6 ; \mathrm{df}=1 ; \mathrm{p}=0,014$ ). We attempted to sketch out a full image of the male and the female patient using results of the khi-square tests. 
The respondents imagined a man under 35 years old (72,3\%) who is thin, irresolute, and who was operated on because of some kind of tumour. Regarding his occupational status, he is an intellectual $(35,4 \%)$, white-collar worker $(19,2 \%)$, or a manual worker $(23,8 \%)$. The following typical brief answer well describes the imagined patient's "colourless" character: "A roughly 30 year-old, skilled labourer, a simple man."

In the case of the male patient, stress was most commonly regarded as the etiological factor $(32,3 \%)$, and $16,9 \%$ of respondents supposed some kind of behavioural risk factor (smoking, nutrition etc.). Regarding events before hospitalization, $73 \%$ of respondents saw no family problems preceding the illness. Stress attributed to men was characteristically ascribed to workplace overwhelm. "He works at a huge construction site as a building engineer, some nights as well, having no time to eat and relax. All burden of the construction project falls on him. When he goes home, he still must hold on, assisting in housework, nurturing children."

Using a loglinear model-setting we analysed the relationship between the respondent's field of study, the patient's gender, and the events in hospital. The threefold interaction proved to be significant (model without the triple interaction does not fit, $\chi^{2}=12,88 ; \mathrm{df}=3 ; \mathrm{p}=0,005$ ). The patient's sex does not influence the response in the same way in the case of psychology students, as for medical students. According to $71 \%$ of medical students, if the man is visited in the hospital by his family, he feels much better and his hospital life continues positively. According to psychology students, the situation is contrary; they imagine a positive outcome in the case of the female patient. In the case of the female patient, just $39 \%$ of medical students imagine a positive effect of a hospital visit made by her family. Nearly the same rate of respondents have the opinion that in spite of the family visit the woman remains dissatisfied with her overall condition. As we attempt to show below, this highlights the ambivalent and differently imagined nature of family relationship in the case of the female patient. In the case of the male patient we are to conclude from these results the less significant nature of family relationships, or perhaps the rejection of conflicts.

While the illness (tumour) in the story does not - neither in professional, nor in lay opinions belong to those diseases that are thought to have a psychosomatic background, remarkably respondents mostly imagined psychological and behavioural causes as an etiology of the disease. Moreover, among the attributed causes, workplace stress stands out. It is worth mentioning that this particular attribution has been the most typical explanation for men's "medically unexplained symptoms" since the $19^{\text {th }}$ century (Shorter, 1993; Courtenay, 2000; Lee and Owens, 2002). In the case of women, these unexplained symptoms have been attributed to family and emotional conflicts. The incomplete representation of symptoms - the 
lack of a precise diagnoses and anamnesis - calls forth the picture of medically unexplained "somatizing" syndrome and psychosomatic illnesses in the respondents' imagination and mobilizes cultural stereotypes in accordance with this hundred years old tradition. However, other characteristic features of somatization - such as complaining, frequent symptom perception and medical visits - do not appear in the character-painting of the male patient.

\section{The image of the ,somatizing” woman}

The characteristics of the imagined woman called forth by the short story are much more complex compared to the male patient's image. She is around 35 years old, thin and attractive $(35 \%)$, inactive $(25 \%)$ or working in the service industries $(24 \%)$, introverted, irresolute $(51 \%)$, depressed and dissatisfied, and because of presumed problems feels lonely in her relationship. Physically she has some gynaecological problems, but she does not have a serious disease behind her specific complaints. The image of the female patient is constructed by a consequent interactions of certain characteristics. Such relationship could be found between well-groomed appearance and gynaecological problem $(\chi 2=10,6 ; \mathrm{df}=4 ; \mathrm{p}=0,03)$, and between attractiveness and positive outcome of the story $(\chi 2=12,8, \mathrm{df}=5 ; \mathrm{p}=0,025)$. Such relationships show that if an attractive female has an attributed disease, it is very likely to be a gynaecological problem. Also, that in an attractive female's story, the further development of her life is very likely to be imagined as positive.

Furthermore, we found a relationship between fear of loneliness and selfishness $(\chi 2=13,5$; $\mathrm{df}=6 ; \mathrm{p}=0,036)$, and between the story's negative development and selfishness $(\chi 2=20,3$; $\mathrm{df}=10 ; \mathrm{p}=0,026)$. This might be interpreted as the prevalence of the fear of loneliness and from lack of love being much lower in the case of a woman who is capable of being attentive to others. The responses show that according to medical and psychology students, depression and marital problems created the background for the woman's stress. „She has marital problems, her husband neglects her. Probably, hypochondriac symptoms developed as a response to that. ...Depressing things happened to her, her marriage broke down, she became exhausted, depressed." The results of representative surveys regarding the state of mental health in the Hungarian population highlight that one of the most serious health problems among young women is depression (Purebl and Balog, 2008). It is important to point out that in the case of a male patient, respondents imagined work-related problems as a background and cause of stress; on the other hand in the case of a female patient, they imagined the cause 
of stress within the family and her interpersonal relationships. Thus the male patient more frequently appears in an independent role, situated outside his family (as a worker), while the female patient appears as a part in family conflicts, or as a dependent person: did not learn to be on her own, her subjective well-being depends on others". Her mental tensions, even personal ones, originate from marital or emotional problems that are not related to work, as in the case of the man. The female respondents mentioned this category as a reason when setting the background of the disease. Moreover, in the case of the male patient, respondents frequently mention behavioural risk factors as a cause of the tumour, which presupposes a degree of individual responsibility in becoming ill. Women primarily appear in the representations as a victim of their own emotions and their marital and interpersonal relationships.

\begin{tabular}{|c|c|c|c|c|c|c|c|}
\hline & \multicolumn{6}{|c|}{ Previous events } \\
\hline & & \multicolumn{2}{|c|}{ No allusion } & \multicolumn{2}{|c|}{ Psysical symptoms } & \multicolumn{2}{|c|}{ Several medical visits } \\
\hline & & Count & Row \% & Count & Row \% & Count & Row \% \\
\hline \multirow{2}{*}{$\begin{array}{l}\text { Patient's } \\
\text { gender }\end{array}$} & male & 90 & $69,2 \%$ & 36 & $27,7 \%$ & 4 & $3,1 \%$ \\
\hline & female & 67 & $36,6 \%$ & 96 & $52,5 \%$ & 20 & $10,9 \%$ \\
\hline
\end{tabular}

\section{Table 3: Connection between the events before getting into hospital and the patient's gender}

As it is shown in Table 3, according to respondents, the female patient frequently had physical complaints and had several visits to her doctor before hospitalization $(\mathrm{p}<0,001)$. Respondents attributed nearly twice as many preceding symptoms, and three times more medical visits, to the female patient, compared with the male patient. This result coincides with the statistically proven health behaviour of women that shows women having an increased perception of symptoms and more frequent visits to their doctor. These behaviours might originate in their early socialization, in their traditional sexual and social position, and also might be related to biological factors, like birth and menstruation (Gijbers van Wijk et al., 1996; Springer et al., 2012). The incomplete presentation of symptoms in the short story with the female patient call forth in full measure the typical lay and professional representations regarding somatization. Table 4 briefly summarizes the main points of our results. 


\begin{tabular}{|l|c|c|}
\hline $\begin{array}{c}\text { questionnaire } \\
\text { items \& } \\
\text { numbers }\end{array}$ & Male & Female \\
\hline age, n.5 & under 35 year & around 35 year \\
\hline occupation, n.6 & $\begin{array}{c}\text { intellectual; manual worker; white-collar } \\
\text { worker; }\end{array}$ & inactive; service industry \\
\hline $\begin{array}{l}\text { internal/external } \\
\text { characteristics, } \\
\text { n.7 }\end{array}$ & thin, irresolute & thin, attractive \\
\hline diagnosis, n.8 & tumour & gyneacological problem \\
\hline etiology, n.9. & $\begin{array}{c}\text { stress, workplace problem; behavioural } \\
\text { risk factors }\end{array}$ & family problems \\
\hline
\end{tabular}

Table 4: Gender stereotypes and symptom interpretations

As it has been highlighted in other studies, gender stereotypes are not independent from their concrete social and cultural milieu (Flick, 2000). As a brief reference to the concrete context of our study, in Hungarian society - especially age under 35 - traditional gender roles are still robust. According to the Hungarostudy 2006 Survey, in the social representation of man, he has the breadwinner role, and woman is caring for the children and family life (Susánszky et al., 2009). The results of our study are also show the significant influence of traditional gender roles in the interpretation of symptoms, as the etiology of man's symptoms were workplace related problem compared to the etiology of woman, where family problems were emphasized.

\section{Conclusions}

Interestingly, our respondents supposed existential and personal problems (stress, depression, marital conflict, loneliness) as an etiological explanation for a clearly physical symptom presented in the short story. In the case of a male patient, responses are mostly characterized by a psychologizing style of attribution. It was most characteristic in the case of a female patient that the image of the protagonist has been repainted to a somatizing woman after the operation. According to our view, the reason for this could be found in the gender stereotypes regarding somatization, and also in the scarcity of information regarding the presented disease.

In the development of a diagnosis and medical opinion the manner of symptom presentation and the structure of information are determining factors. In this study we presented few but concrete pieces of information regarding the disease. In our earlier study on somatization we presented in a fictional disease-monologue numerous pieces of information regarding 
symptoms in a rather diffuse way, which was constructed along the DSM-IV R's description of „somatization disorder” (Csabai, 2005). Both approaches in our studies seemed to work well in producing projections, psychosomatizing stories that infiltrate prejudices and cultural stereotypes, especially gender stereotypes. Our results are in agreement with other studies which suggest that if the gender of the patient is female, somatizing attributions have a greater chance to appear (Wilcox, 1992; Martin and Lemos, 2002; Chiaramonte and Friend, 2006).

Our results are valuable primarily because of the role gender stereotypes play within the the doctor-patient, and therapist-client relationship. We rarely found significant differences regarding the development of professional opinion among students of the two fields (medicine and psychology). This similarity is interesting in light of the two fields' separate and different professional socialization. The lack of significant differences between the groups might be explained by the respondents' not yet fully developed professional identity, their transitional professional/lay status, which gives more space to the impact of cultural representations and gender stereotypes. However, as we already referred, even in the case of doctors the very same stereotypes emerged as in the case of laypersons, a finding that highlights a need to readjust the process of professional socialization.

According to Foss and Sundby (2003) women have a more detailed symptom presentation, they are more engaged with their symptoms, they have more frequent medical visits, and they are more likely to be dissatisfied with their medical care. Female patients' dissatisfaction with their medical care might be a result of the negative attitude of hospital staff who approach women with specific prejudices. Hospital staffs usually approach men more positively, men's wards are seen as having a better atmosphere, and disease is not a topic in general discussions (Foss and Sundby, 2003). As our results have shown, gender stereotypes are present even in the transitional stage of professional socialization - independently of the two fields of study where these stereotypes could be effectively readjusted in education and teaching. Gender stereotypes have an increasing impact if information regarding the particular disease is less available, or badly structured and diffuse. As a practical consequence of our study, we suggest supporting both parties in the doctor-patient relationship in providing more precise, welldetailed and adequately structured anamnesis during medical consultations. Both psychology and medical students should be able to recognize their gender stereotypes and prejudices that affect their development of a diagnosis and professional opinion. 


\section{References}

Addis M and Mahalik JR (2003) Men, masculinity, and the contexts of help seeking. American Psychologist 58 (1):5-14.

Arksey H (2008) Expert and lay participation in the construction of medical knowledge. Sociology of Health and Illness 16 (4): 448-468.

Aronowitz RA (1998) Making sense of illness. Science, society and disease. Cambridge University Press, Cambridge.

Bishop GD, Briede C, Cavazoz L, Grotzinger R and McMahon S (1987) Processing illness information: the role of disease prototypes. Basic and Applied Social Psychology 8: 21-43.

Chiaramonte GR and Friend R (2006) Medical Students' and Residents' Gender Bias in the Diagnosis, Treatment, and Interpretation of Coronary Heart Disease Symptoms. Health Psychology 25 (3): 255-266.

Courtenay WH (2000) Constructions of masculinity and their influence on men's well-being: a theory of gender and health. Social Science and Medicine 50:1385-1401.

Creed F and Barsky A (2004) A systematic review of somatization disorder and hypochondriasis. Journal of Psychosomatic Research 56: 391-408.

Csabai M and Szili K (2010) The Interdependent Roles of Expert and Lay Knowledge in the Process of Trying to Make Sense of Medically Unexplained Symptoms. In: Kalitzkus V and Twohig P (Eds.), The Fallible Body: Narratives of Health, Illness and Disease (pp. 229-241.) Inter-Disciplinary Press, Oxford.

Csabai M (2005) Lay and Professional Discourses about "Medically Unexplained" Symptoms. The Need for New Participatory Techniques in Communication. In: Rubinelli S and Haes J (Eds.), Tailoring Health Messages. Bridging the Gap Between Social and Humanistic Perspectives on Health Communication. (pp. 165-171.) Health Care Communication Laboratory, Universita della Svizzera Italiana, Lugano.

CsörszI, Molnár P andCsabai M (2011) Medical students on the stage. An experimental performative method for the development of relational skills. Medical Teacher 33:489-494. 
Derose KP, Rays DH, McCaffrey DF and Baker DW (2001) Does physician gender affect satisfaction of men and women visiting the emergency department? Journal of General Internal Medicine 16 (4): 218-226.

Dijkstra AF, Verdonk P and Laro-Janssen AL (2008) Gender bias in medical textbooks Examples from coronary heart disease, depression, alcohol abuse and pharmacology. Medical Education 42: 1021-1028.

Fletcher RJ, Higginbotham N and Dobson A (2002) Men's perceived health needs. Journal of Health Psychology 7: 233-241.

Flick U (2000) Qualitatove Inquiries into Social representations of Health. Journal of Health Psychology 5 (3): 315-324.

Foss C and Sundby J (2003) The construction of the gendered patient: hospital staff's attitudes to female and male patients. Patient Education and Counseling 49 (1): 45-52.

Gijsbers van Wijk CMT, Huisman H and Kolk AM (1999) Gender differences in physical symptoms and illness behavior. A health diary study. Social Science and Medicine 49 (8): $1061-1074$.

Gijsbers van Wijk CMT, Van Vliet KP and Kolk AM (1996) Gender perspectives and quality of care: towards appropriate and adequate healthcare for women. Social Science and Medicine 43 (5): $707-720$.

Hall JA and Roter DL (1998) Medical communication and gender: a summary of research. Journal of Gender Specific Medicine 1 (2): 39-42.

Hamberg K, Risberg J and Johansson EE (2004) Male and female physicians show different patterns of gender bias: A paper case-studyof management of irritable bowel syndrome. Scandinavian Journal of Public Health 32 (2): 144-152.

Jenkins J and Oatley K (2006) Understanding Emotions. Malden, MA: Wiley-Blackwell.

Kerssens JJ, Bensing JM and Andela MG (1997) Patient preference for genders of health professionals. Social Science and Medicine 44 (10): 1531-1540.

Lee C and Owens RG (2002) Issues for a psychology of men's health. Journal of Health Psychology 7 (3): 209-217. 
Mar RA, Oatley K and Peterson JB (2009) Exploring the link between reading fiction and empathy: Ruling out individual differences and examining outcomes. Communications 34: 407-428.

Martin R and Lemos K (2002) From heart attacks to melanoma: Do common sense models of somatization influence symptom interpretation for female victims? Health Psychology 21: $25-32$.

Meeuwesen L, Bensing J and Van Den Brink-Muinen A (2002) Communicating fatigue in general practice and the role of gender. Patient Education and Counseling 48: 233-242.

Patterson CH (1985) The therapeutic relationship. Monterey, CA: Brooks/Cole

Peters S, Stanley I, Rose M and Salmon P (1998) Patients with medically unexplained symptoms: Sources of patients' authority and implications for demands on medical care. Social Science and Medicine 46 (4-5): 599-565.

Prior L (2003) Belief, knowledge and expertise: the emergence of the lay expert in medical sociology. Sociology of Health and Illness 25: 41-57Purebl Gy and Balog P (2008) A depressziós tünetegyüttes jelentősége az esélyteremtés szempontjából. In: Kopp M. (szerk.). Magyar Lelkiállapot 2008. Esélyerôsités és életminôség a mai magyar társadalomban (pp.584-592). Budapest: Semmelweis Kiadó (in Hungarian)

Robbins JM and Kirmayer LJ (1991) Attributions of common somatic symptoms. Psychological Medicine 21 (4): 1029-1045.

Roter DL (2001) How physician gender shapes the communication and evaluation of medical care. Mayo Clinic Proceedings 76 (7): 673-676.

Roter DL, Hall JA and Aoki Y (2002) Physician gender effects in medical communication. A meta-analytic review. Journal of the American Medical Association 288 (6): 756-764.

Ruiz MT and Verbrugge LM (1997) A two way view of gender bias in medicine. Journal of Epidemiology and community Health 51 (2): 106-109.

Shorter E (1993) From paralysis to fatigue. A history of psychosomatic illness in the modern era. The Free Press, New York. 
Sleath B and Rubin R (2002) Gender, Hispanic ethnicity and physician-patient communication about depression and anxiety in primary care. Patient Education and Counseling 48: $243-252$.

Springer KW, Hankivsky O and Bates LM (2012) Gender and health: Relational, intersectional, and biosocial approaches. Social Science and Medicine 74 (11): 1641-1666.

Susánszky A, Susánszky É, Kopp M (2009) Mitől szoronganak a magyar férfiak? A férfi nemi szerep stresszjellegzetességei. Lege Artis Medicinae 19 (6-7): 431-435. (in Hungarian)

Van Den Brink-Muinen A, Van Dulmen S, Messerli-Rohrbach V and Bensing J (2002) Do gender-dyads have different communication patterns? A comparative study in WesternEuropean general practice. Patient Education and Counseling 48 (3): 253-264.

Wilcox VL (1992) Effects of patients' age, gender, and depression on medical students' beliefs, attitudes, intentions, and behavior. Journal of Applied Social Psychology 22: 10931110. 